\title{
Solids Formation on Filtrate Neutralization
}

by

H. P. Holcomb

E. I. du Pont de Nemours and Company

Savannah River Site

Aiken, South Carolina 29808

\section{INFORMATION ONLY}

\section{RECEIVED \\ OCT 221998 \\ OSTI}

\section{DISCLAIMER}

\begin{abstract}
This report was prepared as an account of work sponsored by an agency of the United States Government. Neither the United States Government nor any agency thereof, nor any of their employees, makes any warranty, express or implied, or assumes any legal liability or responsibility for the accuracy, completeness, or usefulness of any information, apparatus, product, or process disclosed, or represents that its use would not infringe privately owned rights. Reference herein to any specific commercial product, process, or service by trade name, trademark, manufacturer, or otherwise does not necessarily constitute or imply its endorsement, recommendation, or favoring by the United States Government or any agency thereof. The views and opinions of authors expressed herein do not necessarily state or reflect those of the United States Government or any agency thereof.
\end{abstract}

\section{DOE Contract No.}

This paper was prepared in connection with work done under the above contract number with the U. S. Department of Energy. By acceptance of this paper, the publisher and/or recipient acknowledges the U. S. Government's right to retain a nonexclusive, royalty-free license in and to any copyright covering this paper, along with the right to reproduce and to authorize others to reproduce all or part of the copyrighted paper.

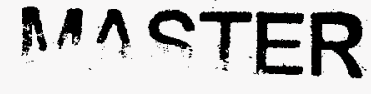




\section{DISCLAIMER}

Portions of this document may be illegible in electronic image products. Images are produced from the best available original document. 
DPSP $-88-272-61$

May 26,1988

TO: M. TOMAS, $246-\mathrm{F}$

FROM: H. P. HOLCOMB, 772-F Het

SOLIDS FORMATION ON FILTRATE NEUTRALIZATION

INTRODUCTION AND SUMMARY

You requested the Separations Technology Laboratory to study what happens when a filtrate solution, which will be a F B-Line product, is neutralized with sodium hydroxide. You were primarily concerned about the formation of solids that could cause damage in pump seals, resulting in their failure.

We prepared, according to the recipe furnished us, a synthetic filtrate solution containing nitric acid, hydroxylamine nitrate, hydroxylamine sulfate, hydrofluoric acid, and ascorbic acid.

The solution was studied in two ways. For the first test, the solution was titrated with $50 \% \mathrm{NaOH}$, scheduled to be the process neutralizing agent. $\mathrm{pH}$ changes during the titration were monitored. As requested, a 25 volume percent excess of caustic was also slowly added to the solution once $\mathrm{pH} 7$ was obtained. No solids had formed after the neutralized solution had stood for 3 days. This information was reported to you in my memorandum of May 2.

However, after 5 days of standing, white needlelike solids appeared in the mother liquor. These solids were determined to be approximately $90 \%$ sodium oxalate and $10 \%$ sodium fluoride. Although oxalate ion was not present in the original chemicals used to prepare the synthetic solution, it was formed, substoichiometrically, from the reaction between nitric acid (1.8M) and ascorbic acid $(0.4 \mathrm{M})$ in the synthetic solution. According to $\mathrm{R}$. M. Wallace, SRL Research Fellow, oxalate can be one of the reaction products: in the oxidation-reduction reaction between these two.

The second test more closely approximated process conditions and used the same quantities of solutions employed for the first test. For this test, caustic was added rapidly to the stirred filtrate solution. The entire quantity of caustic, 25 volume percent excess included, was added over a period of 10-15 seconds. The temperature 
DPSP $-88-272-61$

M. TOMAS

Page 2

May 26, 1988

rise was from $30^{\circ} \mathrm{C}$ to $83^{\circ} \mathrm{C}$, and no solids were immediately noted. After one hour, some solids were observed on the bottom of the reaction vessel. After 24 hours, about the same quantity was noted. The solids were granular and appeared to be crystalline. Analysis by $x$-ray diffraction indicated the solids to be almost entirely sodium fluoride, NaF.

The clear, solids-free supernate from each test was stored in the laboratory. Over a 3 -week period, white solids slowly formed and settled to the bottom of both flasks. The solids appeared similar to each other. Samples were submitted for x-ray diffraction analysis. Both solids were identified as being comparable in composition to the solids initially formed following the rapid addition of caustic to the synthetic filtrate. Those were mostly sodium oxalate with some sodium fluoride. Therefore, slow postprecipitation of these solids might prove a problem if such neutralized filtrate solutions were stored for some length of time.

Other parametric studies were made. These include scanning electron microscopy (SEM) of the solids as well as cationic and anionic analyses of their water solutions. SEM was also employed to ascertain the particle size range of the two solids. Details of these studies appear in the body of this report.

In summary, the results of our experiments indicate that under process conditions, granular, crystalline sodium fluoride will be produced by rapid neutralization of the filtrate solution with $50 \% \mathrm{NaOH}$ plus a 25 volume percent excess. Postprecipitation of sodium oxalate-sodium fluoride and its accumulation can occur over a three-week storage period of the neutralized filtrate. Such solids could pose operational problems from pump seal abrasion and potential failure caused by them.

\section{EXPER IMENTAL}

\section{Synthetic Filtrate Solution}

The composition of the filtrate solution to be tested was furnished as :

$$
\begin{aligned}
& \text { 1.8 } \mathrm{HNO}_{3} \\
& 0.1 \mathrm{M}\left(\mathrm{NH}_{2} \mathrm{OH}\right)_{2} \cdot \mathrm{H}_{2} \mathrm{SO}_{4} \quad \text { (HAS) } \\
& 0.1 \mathrm{M} \mathrm{NH} 2 \mathrm{OH} \cdot \mathrm{H}_{2} \mathrm{SO}_{4} \quad \text { (HAN) } \\
& 0.8 \mathrm{M} \mathrm{HF} \\
& 0.4 \mathrm{M} \mathrm{C} \mathrm{CH}_{6} \mathrm{H}_{6} \text { (Ascorbic Acid). }
\end{aligned}
$$

Each test solution was prepared in the same manner. To approximately $150 \mathrm{~mL}$ of water was added $3.3 \mathrm{~g}$ of solid hydroxylamine sulfate, $11.1 \mathrm{~mL}$ of $1.8 \mathrm{M}$ hydroxylamine nitrate, $14 \mathrm{~g}$ of ascorbic acid, and $5.8 \mathrm{~mL}$ of $27.6 \mathrm{M} \mathrm{HF}$. Following dissolution of the solids 
DPSP $-88-272-61$

M. TOMAS

Page 3

May 26, 1988

via magnetic stirring, $23 \mathrm{~mL}$ of $15.7 \mathrm{M} \mathrm{HNO}_{3}$ was slowly added to the stirred solution. The solution was finally diluted to 200 $\mathrm{mL}$ with deionized water.

As nitric acid was being added during preparation of both test solutions, there was a small quantity of $\mathrm{NO}_{\mathrm{X}}$ released, indicating a reaction between the nitric acid and one of the solution components. The reaction was neither vigorous nor rapid. Nitric acid was interacting with ascorbic acid to a slight extent, resulting in the small quantity of brown fumes.

$50 \%$ (19M) $\mathrm{NaOH}$, to be used as the process neutralizing agent, was prepared by dissolving reagent-grade $\mathrm{NaOH}$ in deionized water. The solution was allowed to cool to room temperature prior to use.

Test \#1 - Titration of Synthetic Filtrate with $50 \% \mathrm{NaOH}$

This test was described in my May 2 memorandum to you. I shall repeat our procedure and latest findings since solids did not form in the neutralized solution for the first 3 days, but were present after 5. My previous memo reported only the results after 70 hours of standing. The solids formed later.

$200 \mathrm{~mL}$ of the synthetic filtrate was placed in a $400-\mathrm{mL}$ beaker with a magnetic stirring bar. A 50-mL burette was filled with the $50 \% \mathrm{NaOH}$ solution. The caustic was added very slowly, almost dropwise, to the stirred filtrate. $\mathrm{pH}$ changes in the solution were monitored with an immersed $\mathrm{pH}$ electode and digital $\mathrm{pH}$ meter standardized with $\mathrm{pH} 7$ buffer. The standardization was checked at least twice during the neutralization. Initial pH of the solution prior to any caustic addition was 1.6 .

After $53.9 \mathrm{~mL}$ of $50 \% \mathrm{NaOH}$ had been added to the original synthetic filtrate, the $\mathrm{pH}$ of the solution was 7.06 ; thus, it had been neutralized. No solids were noted at this point. Then, for the 25 volume percent excess of caustic, $13.5 \mathrm{~mL}$ was slowly added from the burette. After this addition, the $\mathrm{pH}$ of the solution was 11.8 , and its temperature was $50^{\circ} \mathrm{C}$. Total volume was $275 \mathrm{~mL}$. No solids were noted.

The neutralized solution was covered with a watch glass and allowed to stand in the laboratory. Some 70 hours following neutralization, the $\mathrm{pH}$ was 12.8 , and solution volume was $268 \mathrm{~mL}$. No solids were: noted. At this point, the results of this test were reported to you in my May 2 memo.

However, after standing 5 days, a small quantity, estimated to be 1 to $2 \mathrm{~mL}$, of white, somewhat needlelike solids, was noted in the neutralized filtrate. These were allowed to remain in the mother Iiquor until Test 非 2 was completed. 
DPSP $-88-272-61$

M. TOMAS

Page 4

May 26, 1988

A note concerning $\mathrm{pH}$ readings should also be made again. The initial solution was very acidic, and the $\mathrm{pH}$ reading should have been less than the indicated 1.6. Likewise, the neutralized solution with the $25 \%$ excess caustic was calculated to be $0.93 \mathrm{M}$ in $\mathrm{NaOH}$ and should have had a $\mathrm{pH}$ reading quite close to 14 . The $\mathrm{pH}$ electrode being used was an ORION Combination Electrode, Model 91-56. Contact with the ORION Technical personnel yielded the information that was reported to you in my memo of May 2. Due to liquid junction potential, this particular electrode is not rapid in its response to solution pHs below 2 or above 12 . However, it is quite capable of rapid $\mathrm{pH}$ measurement within that range. So, the neutralization curve obtained with its use should be accurate.

Test $\#_{2} 2$ - Rapid Neutralization of Filtrate

Following reporting the results of Test \#1 to you, you requested us to conduct a similar experiment in which all the $50 \% \mathrm{NaOH}$, excess included, was to be rapidly added to the stirred synthetic filtrate, instead of the slow titration conditions of Test 非l.

On conducting Test $\# 2$, the temperature $r$ ise was from $30^{\circ} \mathrm{C}$ to $83^{\circ} \mathrm{C}$. No solids were noted immediately following the caustic addition. However, after one hour, some solids were seen on the bottom of the beaker. The solution temperature at this point was $43^{\circ} \mathrm{C}$. After 3 hours of standing, there appeared to be a few more granularappearing solids. Their color was difficult to discern due to the dark red-amber color of the solution. Its temperature was now $29^{\circ} \mathrm{C}$.

Some 24 hours following the caustic addition, there was approximately $5 \mathrm{~mL}$ of granular solids on the beaker bottom. After 48 hours, conditions were the same.

Washing of Solids and Preparation for Sampling

The solids-containing solutions from both tests were allowed to stand undisturbed so that most of the mother liquor could be removed via decantation. A small amount of each reddish-amber mother liquor was used to transfer the solids to $30-\mathrm{mL}$ graduated centrifuge cones. The slurry was then centrifuged. A photo of the centrifuged solids is shown as Figure 1 (all Figures are in the Appendix). Some $5 \mathrm{~mL}$ of granular, reddish solids resulted from the "rapid" : caustic addition; about $1.5 \mathrm{~mL}$ of white solids resulted from the "slow" caustic addition after the neutralized solution had stood for 5 days. The color of the "rapid" solids is believed due to occlusion or sorption of the neutralized, colored products produced by ascorbic acid degradation. Since the "slow" solids crystallized from solution over a longer period, they were not highly contaminated with these products. 
DPSP $-88-272-61$

M. TOMAS

Page 5

May 26, 1988

The solids, assumed to be sodium salts, would therefore be soluble in water, so aqueous washing was out of the question. The solids in each tube were washed with four $20-\mathrm{mL}$ portions of absolute ethyl alcohol in order to remove as much of the mother liquor as possible. Washing was by vortex mixing, followed by centrifugation, and then, decantation of the wash liquid. The solids were rather insoluble in the alcohol since about as many remained following washing as were present before.

The solids, still in the centrifuge cones, were placed in a drying oven that was at ambient temperature. The temperature inside the oven was slowly brought to $60^{\circ} \mathrm{C}$ and allowed to remain there for 4 hours. Following the drying operation, the solids were free and mobile.

For ICP (Inductively Coupled Plasma) cation analysis and IC (Ion Chromatography) anion analysis, $0.100 \mathrm{~g}$ of each solid was dissolved in deionized water giving a final volume of $5 \mathrm{~mL}$. The sample for ICP was sent to SRL; the IC, to $772-\mathrm{F}$ Labs.

Three sets of samples of the solids were prepared and given to ADD, SRL, for examination by scanning electron microscopy (SEM), for $x$-ray diffraction analysis, and for particle size analysis. However, SRL is not equipped to do the latter, nor can Labs do particle size on aqueous-soluble solids. Particle size analysis on such can be done off-site, but that can take from 4-6 weeks.

The decanted, solids-free supernates from each test, were allowed to stand in the laboratory for 3 weeks. At the end of this time, both solutions contained white, crystalline solids that had postprecipitated from solution during this additional standing period. These solids were washed like those formed initially. Samples of the postprecipitates were submitted only for x-ray diffraction analysis for identification.

\section{RESULTS AND DISCUSSION}

\section{X-Ray Diffraction}

Figures 2 and 3 are spectral patterns produced by the $x$-ray diffraction analysis of the two solids. Figures 4 and 5 are the diffraction patterns obtained from the solids postprecipitated : during the 3 -week standing period.

Figure 2 identifies the solid produced in the NaOH titration test to be mostly $(>90 \%)$ sodium oxalate with a minor quantity of sodium fluoride and a trace of sodium nitrate. 
DPSP $-88-272-61$

M. TOMAS

Page 6

May 26, 1988

Figure 3 likewise identifies the solid produced in the $\mathrm{NaOH}$ rapid addition test to be fairly pure sodium fluoride.

Figures 4 and 5 are quite similar to the pattern of Figure 2, so the postprecipitated solids from both tests were primarily sodium oxalate with some sodium fluoride present.

These tests are quite definitive as to the composition of the solids to be expected from filtrate neutralization.

\section{Ion Chromatography}

Water solutions of each solid were prepared and submitted to Laboratories for anion analysis to assist in ascertaining the solids ' composition as well as to identify other anions present as impurities.

For the sodium oxalate-sodium fluoride solid, a small quantity of both nitrate and sulfate were identified as impurities. The $\mathrm{SO}_{4}^{-2} / \mathrm{NO}_{3}{ }^{-}$weight ratio was about 7 . The sodium fluoride solid also contained the same anionic impurities, but the sulfate/nitrate weight ratio in it was about 17 .

ICP Analysis

Results of the ICP cation analysis showed sodium ion to be the predominant cation present in the water solution of each solid. Silicon was present as a trace element. However, this is to be expected since all the experimental work was conducted in Pyrex ${ }^{\circledR}$ glass containers. Caustic is known to slowly attack glasses, so silicon is suspected to come from the containers' $\mathrm{SiO}_{2}$.

Scanning Electron Microscopy

A foreword of caution is necessary regarding interpreting the results of this analysis. The solids submitted for SEM scans were alcohol-washed by vortex mixing. This mixing action would yield particulates that were not the same size or shape as those originally present in the aqueous solution in which the solids formed. Also, agglomeration characteristics would be changed by going from an aqueous to an alcohol medium. However, we can get some relative differences between the solids as well as get an approximation as to what they were initially like.

Figures 6-9 show photomicrographs of the solids that resulted from the process of caustic neutralization by slow titration. These particulates vary in size from large, porous-appearing agglomerates, approximately $250 \mu \mathrm{m}$ unidimensionally, down to individual crystals some 5-10 $\mathrm{m}$. The scale is at the bottom of each photo and is denoted as the length of the white line. 
DPSP $-88-272-61$

M. TOMAS

Page 7

May 26, 1988

Figures 10-13 are photomicrographs of the particulates that formed shortly after the rapid neutralization of the synthetic filtrate solution with caustic. These photos show particles and agglomerates of various sizes, but ones especially of interest would be the octahedra single crystals that are evident, especially in Figures 10 and 11 . These are some $40 \mu \mathrm{m}$, unidimensionally, and are probably unchanged from the alcohol washing. Some of the smaller ( $10 \mu \mathrm{m}$ or less), more rounded particles, shown in a different field of view in Figures 12 and 13 , are assumed to be the result of the abrading wash action on the single crystals. A part of one of the larger octahedral crystals can be seen in the upper left corner of Figure 12. If these octahedra form during neutralization, they could be very damaging to pump seals, especially if the latter are easily abraded.

\section{CONCLUSIONS}

The neutralization of the synthetic filtrate solution by the rapid addition of $50 \%$ caustic, plus a 25 volume percent excess, does result in solids formation within a period of one hour following neutralization. The solids are primarily sodium fluoride.

If the filtrate solution is allowed to stand for a period of more than 3 weeks, additional solids postprecipitate from solution. The composition of these solids are primarily sodium oxalate (about $90 \%$ ) with sodium fluoride constituting most of the remainder.

The granular, crystalline nature of these solids could pose a definite processing problem if solutions containing them are moved with pumps containing internal seals.

\section{ACKNOWLEDGMENTS}

$A D D, S R L$, is recognized for providing excellent cooperation and analytical services that allowed us to characterize the solids. $P$. Kent Smith gave us rapid service in identifying the solids via $x$-ray diffraction. D. F. Steedly did the SEM work and provided the photomicrographs that constitute part of this report.

P. B. Berry of Laboratories Department oversaw the IC analysis.

R. M. Wallace of DWPFT, SRL, is acknowledged for the information' he provided concerning the chemistry of the interaction between ascorbic acid and nitric acid.

$\mathrm{HPH} / \mathrm{h}$

(Original photomicrographs with MT copy only.) 
DPSP $-88-272-61$

M. TOMAS

Page A-1

May 26, 1988

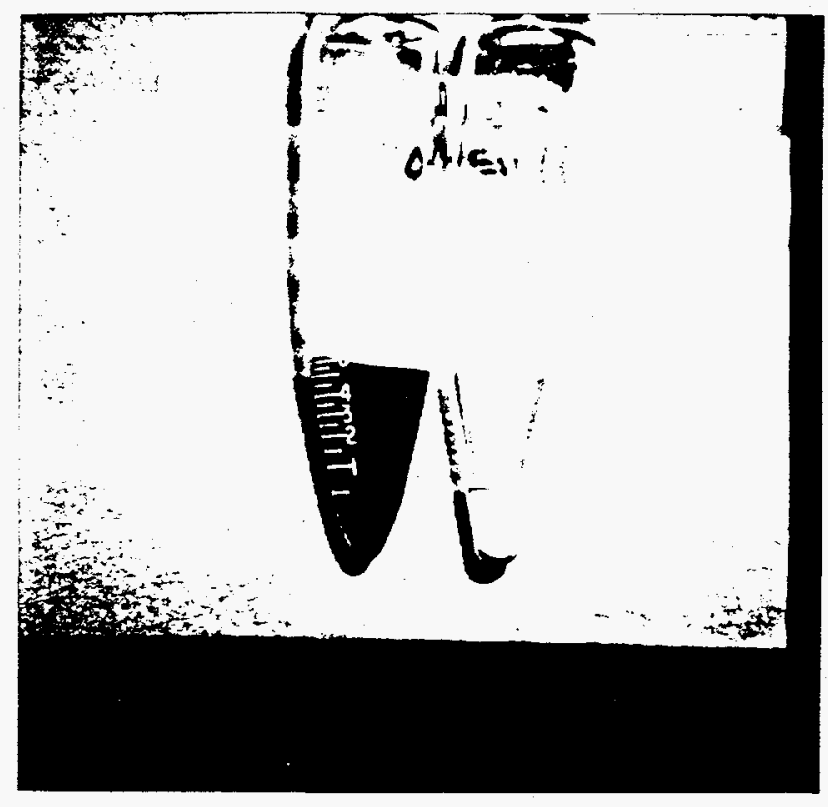

FIGURE 1

Original Solids - Left, Rapid NaOH Addition; Right, Titration 
DPSP $-88-272-61$

M. TOMAS

Page A-2

May 26,1988

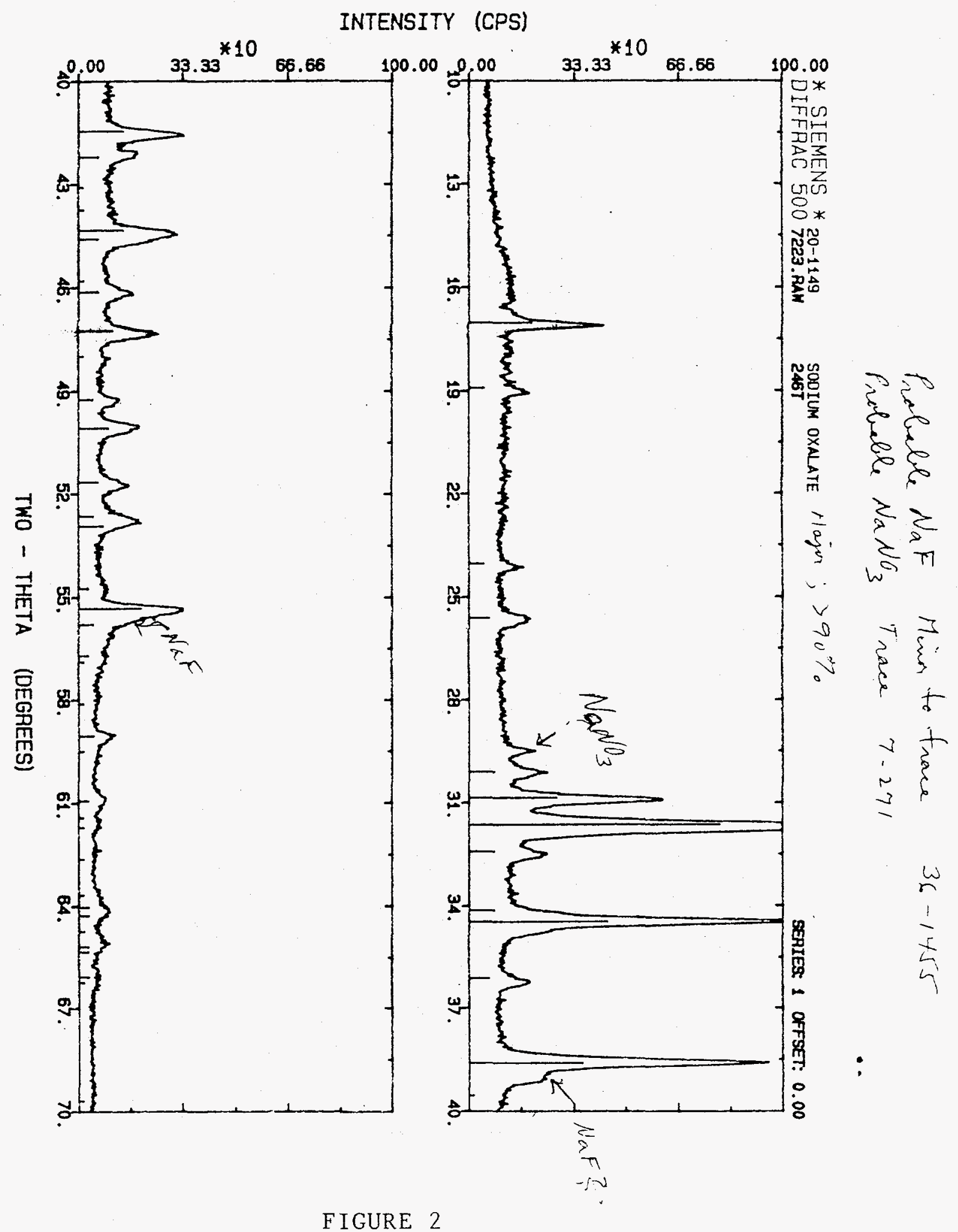

$\mathrm{X}$-Ray Diffraction Pattern - NaOH Titrated

Initial Solids 
DPSP $-88-272-61$

M. TOMAS

Page A-3

May 26,1988

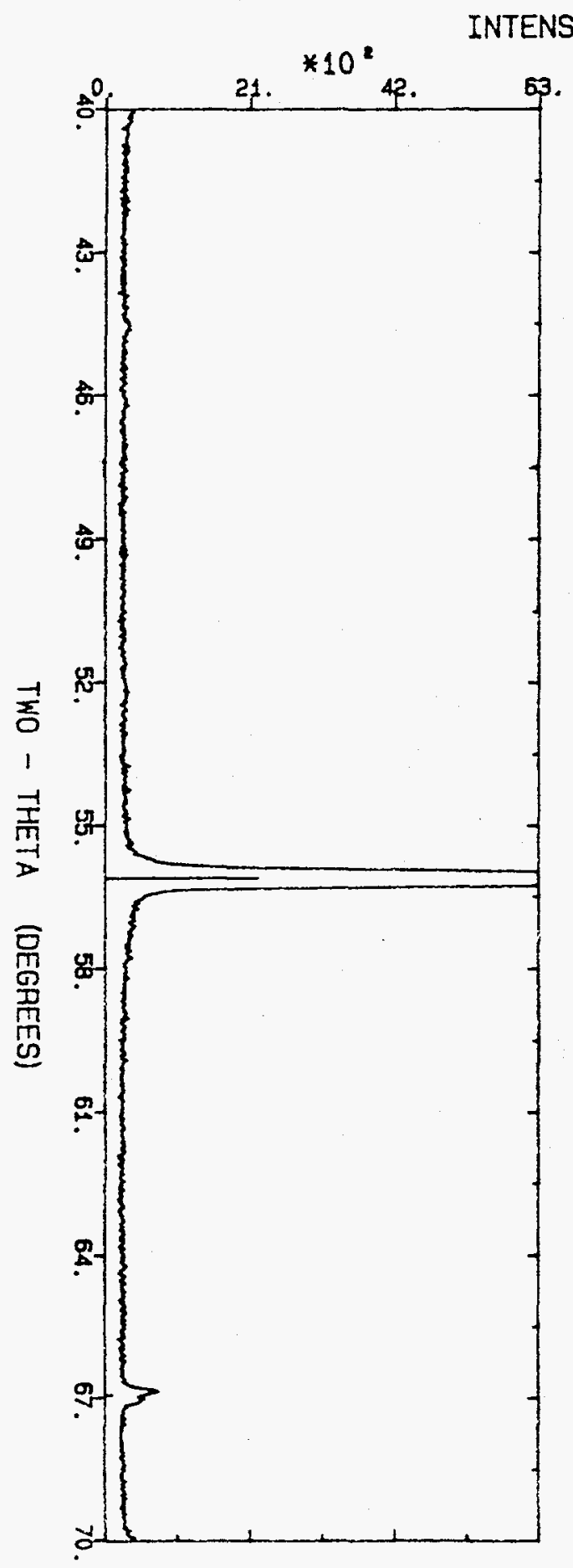

ITY (CPS)

21. ${ }^{\circ} * 10^{2} 42$.

63.

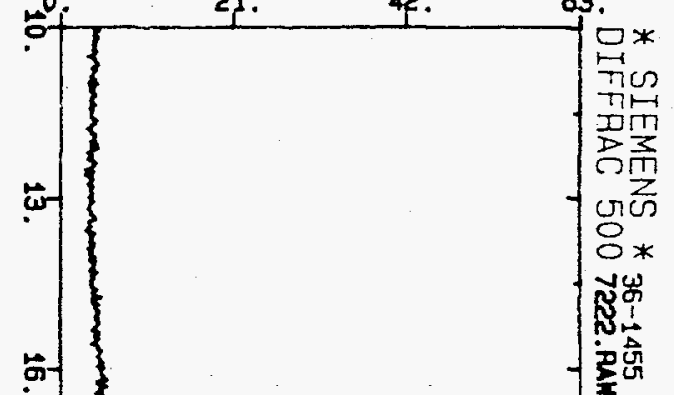

ษ-

:

$:$

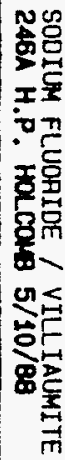

B.

$\omega$

f.

$\frac{F}{r}$

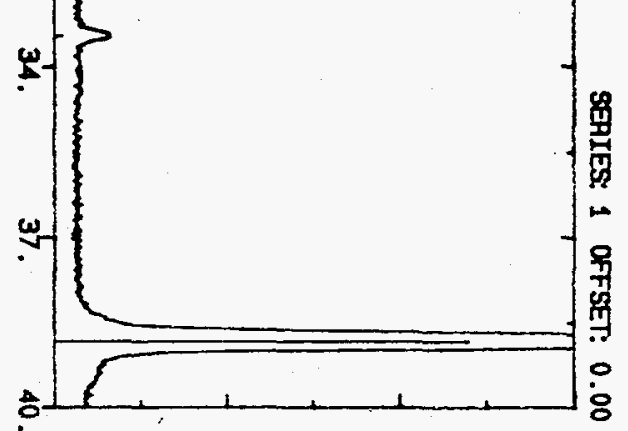

FIGURE 3

X-Ray Diffraction Pattern - NaOH Added Rapidly

Initial Solids 
DPSP $-88-272-61$

M. TOMAS

Page A-4

May 26, 1988

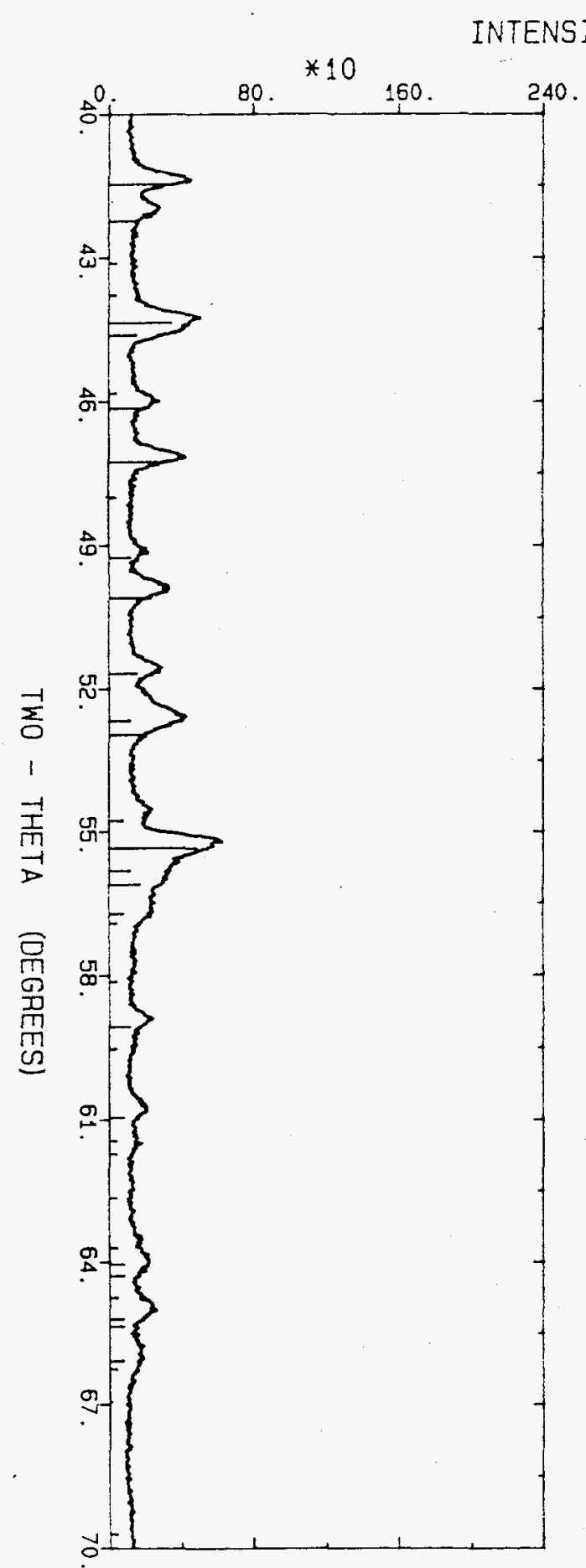

TY (CPS)

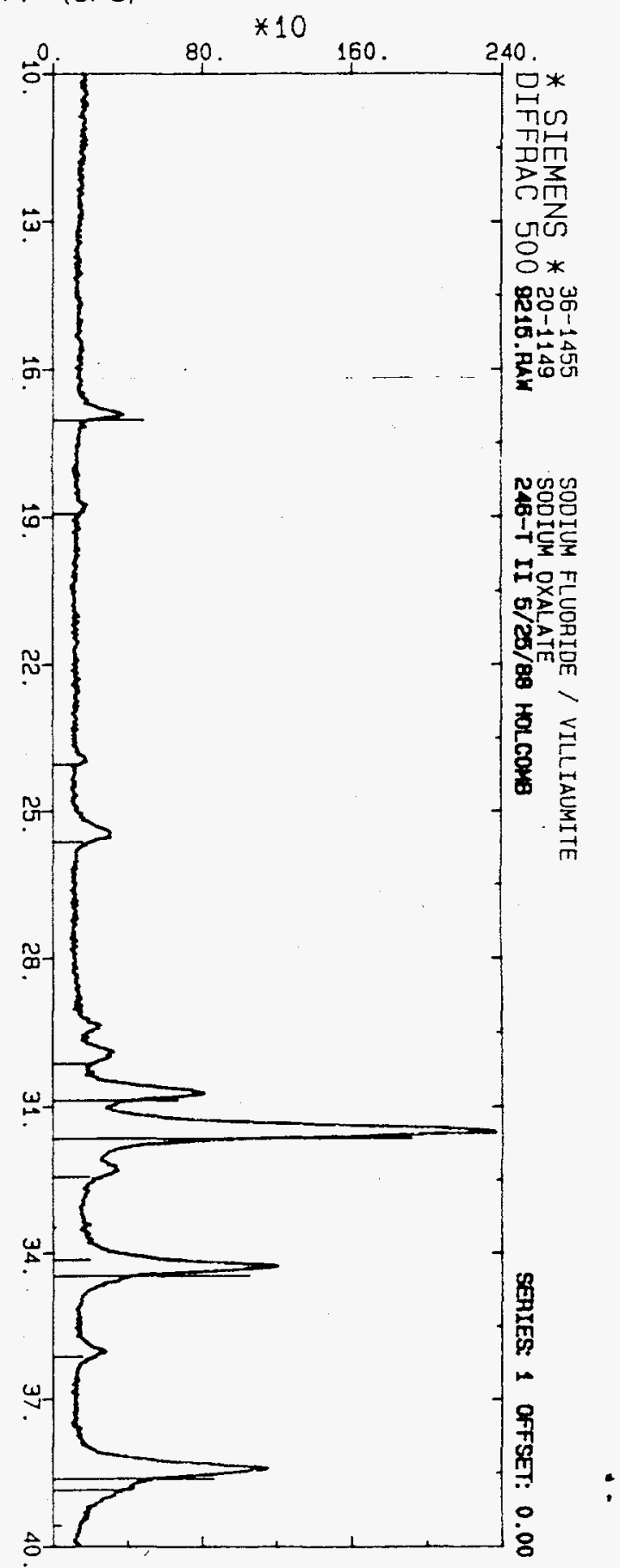

FIGURE 4

X-Ray Diffraction Pattern - NaOH Titrated

Postprecipitated Solids 
DPSP $-88-272-61$

M. TOMAS

Page A-5

May 26,1988

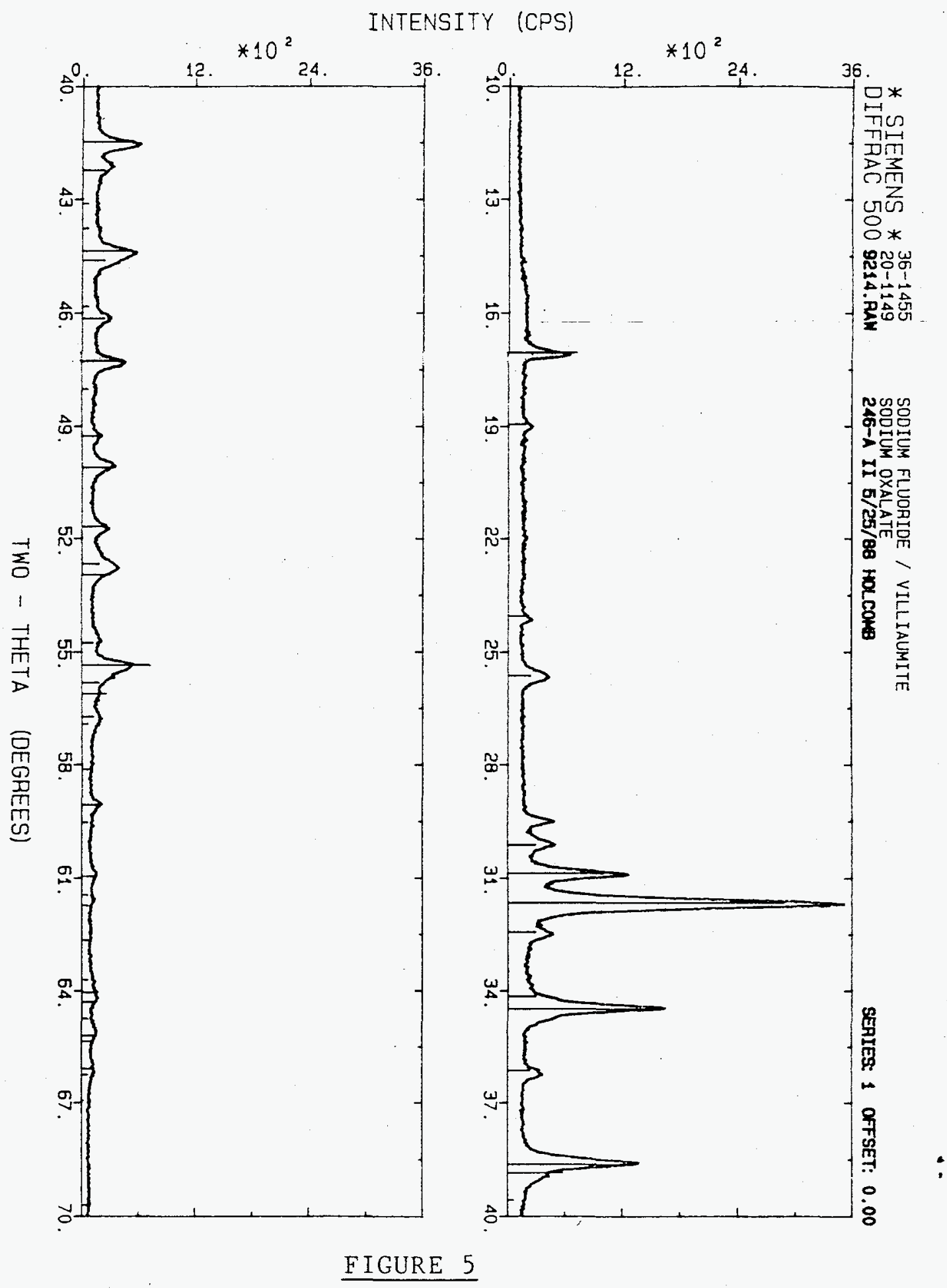

X-Ray Diffraction Pattern - NaOH Added Rapidly

Postprecipitated Solids 
D.P SP $-88-272-61$

M. TOMAS

Page A-6

May 26, 1988

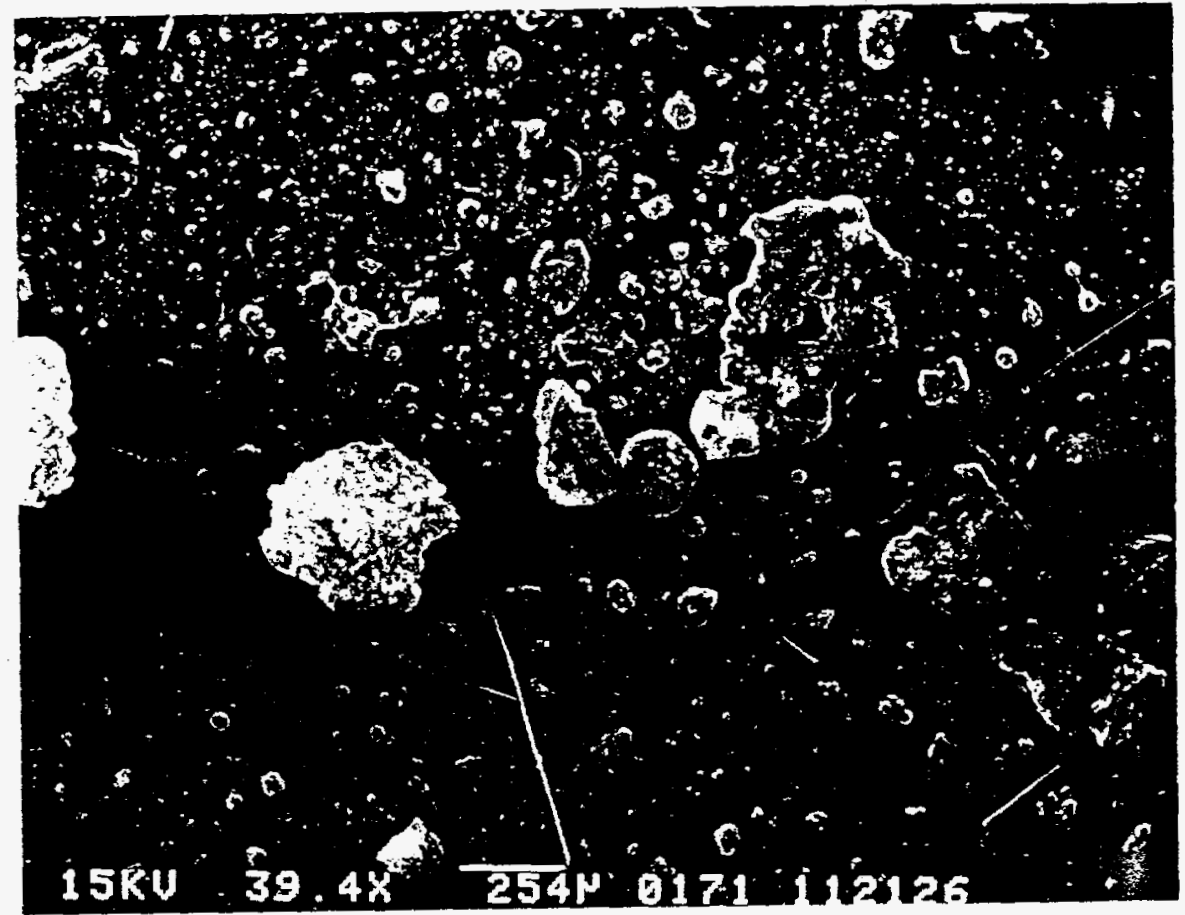

\section{FIGURE 6}

Initial Solids $\mathrm{NaOH}$ Titrated

$39 x$

FIGURE 7

Initial Solids $\mathrm{NaOH}$ Titrated

$250 x$ 
DPSP $-88-272-61$

M. TOMAS

Page A-7

May 26,1988

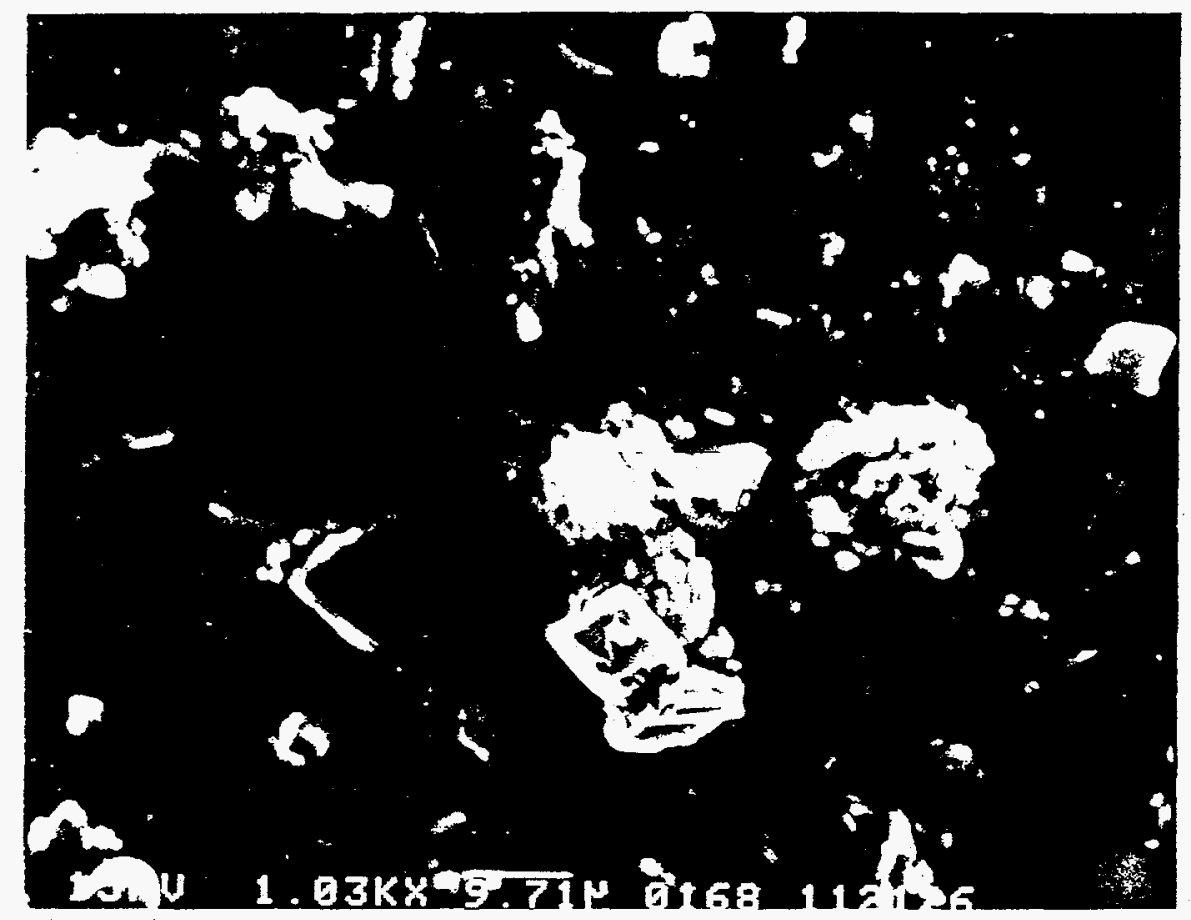

\section{:FIGURE 8}

Initial Solids $\mathrm{NaOH}$ Titrated

$1000 x$

:FIGURE 9

Initial Solids $\mathrm{NaOH}$ Titrated

$2000 x$ 
M. TOMAS

Page A-8

May 26, 1988
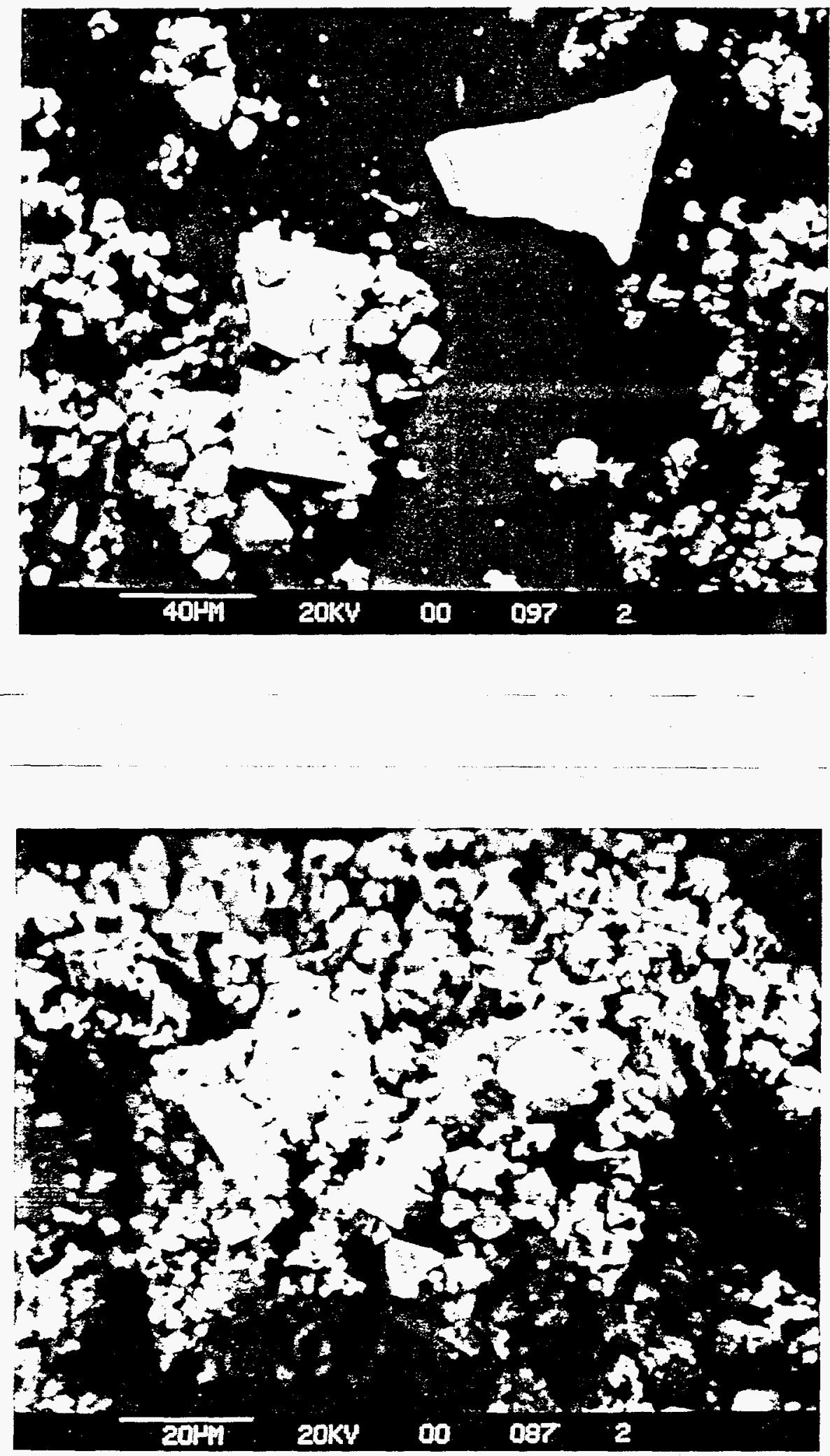

EIGURE 10

Initial Solids -

$\mathrm{NaOH}$ Added Rapidly

$500 x$
FIGURE 11

Initial Solids -

$\mathrm{NaOH}$ Added Rapidly.

$1000 \mathrm{X}$ 
M. TOMAS

Page A-9

May 25, 1988

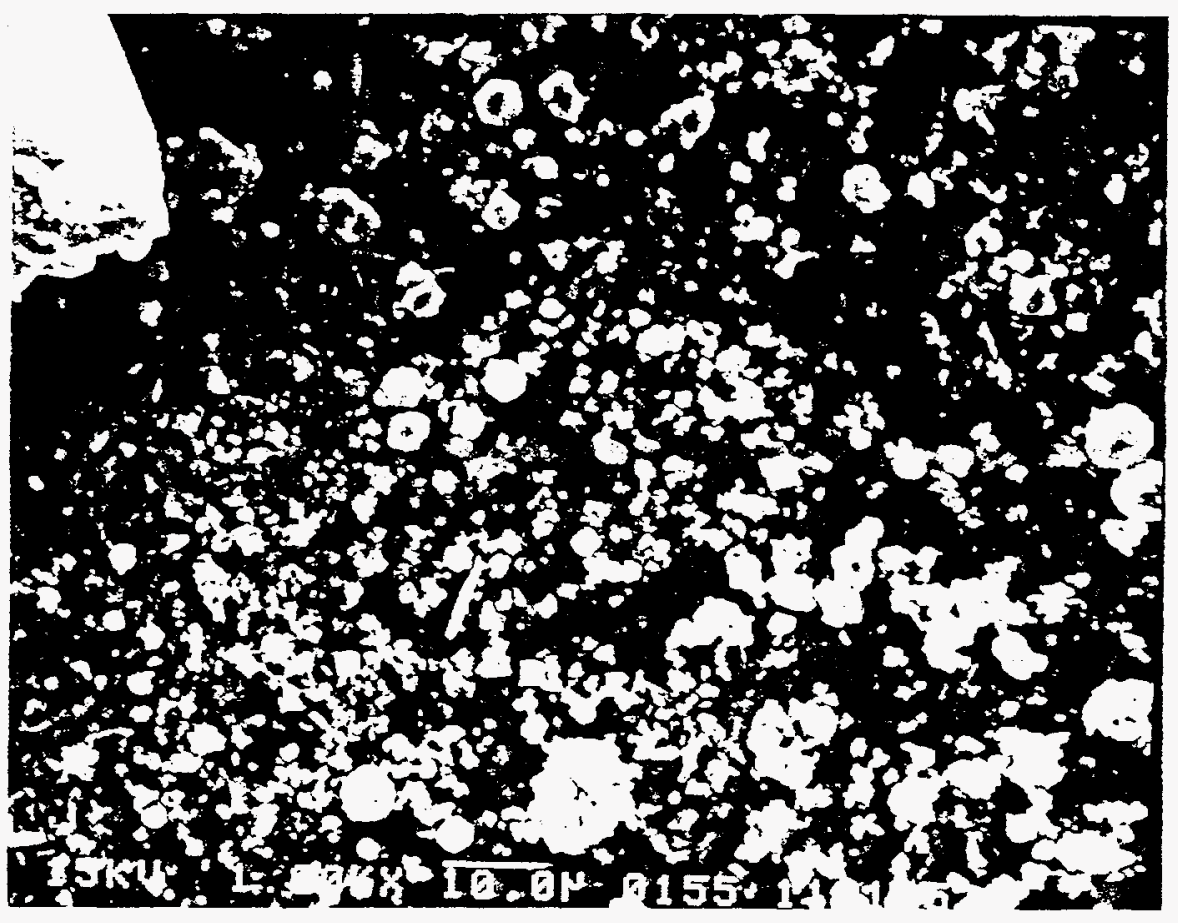

EIGURE 12

Initial Solids -

$\mathrm{NaOH}$ Added Rapidly

$1000 \mathrm{X}$

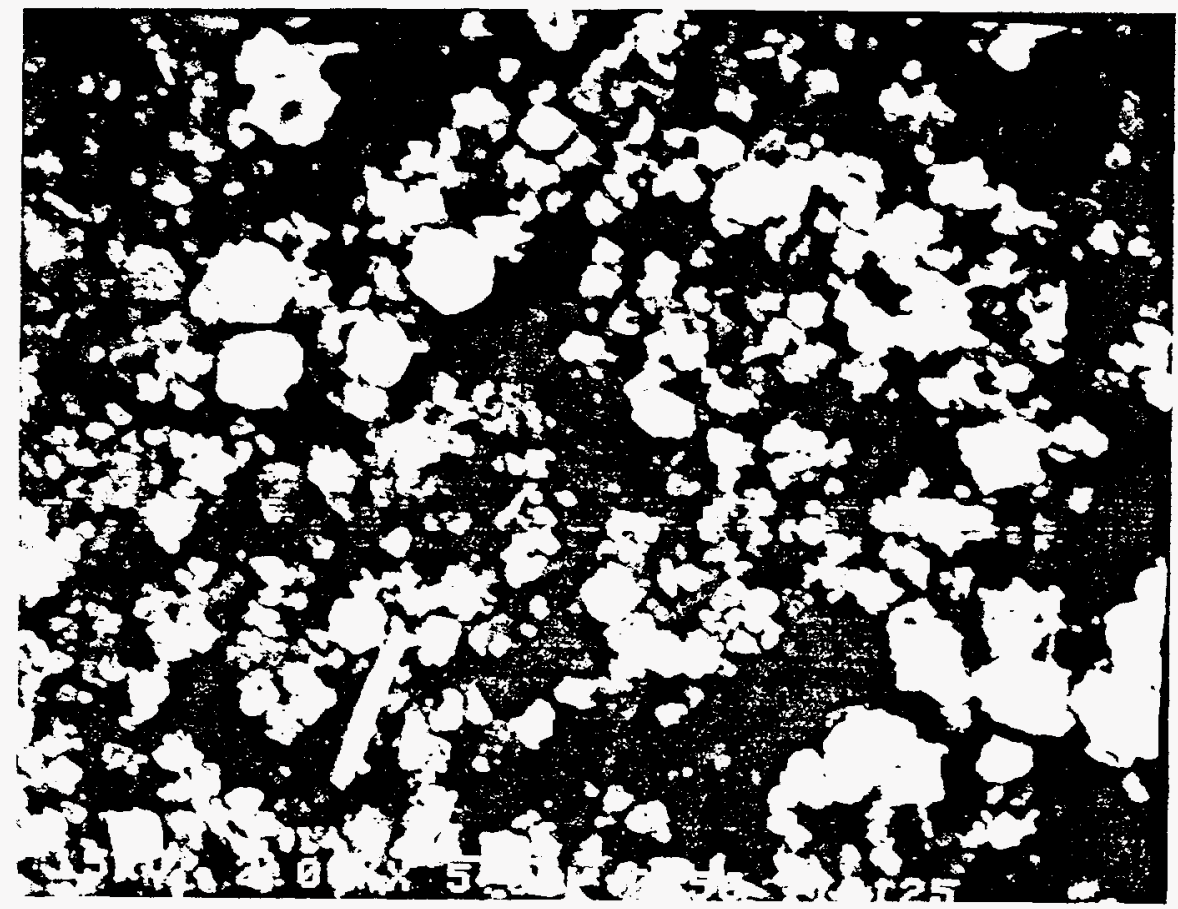

FIGURE 13

Initial Solids -

$\mathrm{NaOH}$ Added Rapidly

$2000 x$ 